\title{
REGULATORY AND FINANCIAL REQUIREMENTSTO SWITCH FROM TRADITIONAL PAYMENT TO ELECTRONIC PAYMENTCASE STUDY IN BAGHDAD MUNICIPALITY BAGHDAD WATER DEPARTMENT
}

Rasha Mahmoud Ali, Dr. Nazem Jawad Abd

Department of Business Administration / College of Business and Economics / University of Baghdad

DOI: $10.37648 / \mathrm{ijrssh} . v 10 \mathrm{i} 01.012$

Received:01 $1^{\text {st }}$ October, 2019; Accepted:31 $1^{\text {st }}$ October, 2019; Published: $21^{\text {st }}$ November, 2019

\section{SUMMARY OF THE RESEARCH}

The topic of e-payment is an important topic in the light of the rapid developments of information and communication technology. light on the requirements of Walt Nzimih and finance for the shift to electronic payment and the extent provided by the Department of water Baghdad / Baghdad Municipality in order to pay the electronic system adoption in the collection of revenue.

The researcher relied on the case study methodology (Case study (As a curriculum science consistent with the research problem and helps the possibility of providing substantive treatment to them, either the research community was represented by ( the Department of Water Baghdad), one of the departments of the Secretariat of Baghdad, and used the checklist Ka main instrument has been relied upon to gather information either methods of analysis of data loss Stability coefficient was used (Cronbach's Alpha)SPIR-MAN grading coefficient, weighted mean, standard deviation and relative importance), and through data collection and analysis, a number of conclusions were reached, most notably that the Baghdad Water Department / Baghdad Municipality possesses the human resources that enable it to shift. To the electronic payment system but suffer from weakness in the human resources training side. The Baghdad Water Department / Baghdad Municipality has the regulatory requirements that enable it to switch to electronic payment system, but suffers from weakness in the financial aspect.

Key words: the requirements of the regulatory and financial, traditional payment, electronic payment. 


\section{INTRODUCTION}

The world is fast and innovative moves which this change has led in all life areas of human, and is the field of information and communications technology is one area that is still evolving rapidly along with the development of technology and science in our time, we have not the emergence of information and communication technology (IT C ( The lives of individuals, institutions and their entire operations. ICTs and digital technologies have made great progress in all fields. The result of this development has been the electronic payment system, as the growth of technology in the payment system has replaced the role of traditional cash (paper currency or coins) with electronic payment instruments that have become more appropriate. E-payment is an important mechanism used by individuals and organizations as a secure and convenient way to make payments online and at the same time a gateway to technological advancement .

Through the above, the importance of the research is highlighted, that although there are studies that deal with electronic payment and the means adopted and the challenges facing it, but did not address the requirements of electronic payment and what is required to adopt this system, it is necessary to highlight them to know what If the organization is able to switch to apply this mega project.

\section{THE FIRST TOPIC: RESEARCH METHODOLOGY}

The research problem:

Iraq is one of the late countries that have gone to the adoption of electronic payment methods compared with the Arab and Western countries and to keep pace with this technical development must know what are the requirements to be met for the possibility of the application of electronic payment in the Secretariat of Baghdad / Baghdad Water Department, especially since the State has begun to move towards this technology during the official directives of the ministries of the Iraqi transition to apply payment to the electro Ni and adopt the means of electronic payment and dissemination of electronic payment culture in the community.

The foregoing raises the main question:
What is the availability of the regulatory and financial requirements in Baghdad Water Department to switch from the traditional payment system to the collection system to the electronic payment system?

Based on the main question in order to know the subject, we ask the following sub-questions:

1- The extent of the application of electronic management in the Baghdad Water Department to the possibility of turning to the system of electronic payment?

2. What is the extent of the support of senior management in the adoption of electronic payment system?

3. What are the requirements for switching to electronic payment system?

4. What are the electronic payment methods?

5. The extent to respond to developments and accept technological change?

\section{Second: The Importance of Research:}

The importance of the research is reflected in the fact that it presents a modern topic that keeps pace with contemporary developments in the technological transformation using modern means of payment to develop the work of governmental and nongovernmental institutions, which achieves positive results in the quality of service provided to citizens in addition to the state's tendencies to work with the application of electronic payment methods in all relevant government institutions. The researcher devises the importance of the research as follows:

1- To provide a conceptual theoretical framework on the electronic payment system and what modern electronic payment methods are and their application.

2. Research helps in spreading and raising awareness of the subject of electronic payment methods to keep pace with technological development as it has become a requirement of the times.

3. The research helps in developing the work of the researched organization by knowing the modern electronic procedures and methods that simplify the procedures of collecting the service provided to citizens and encouraging them to pay bills. 
4. Enrich the Iraqi library and the Arab library in the possibility of switching to the use of modern technological methods of electronic payment methods and their application, especially in government institutions.

\section{Research Objectives}

In the light of identifying the problem and the importance of the research, the main objective of the research is to diagnose the feasibility of applying the electronic payment system and what are the requirements to be met.

1- Knowing what are the necessary requirements that must be met in the organization to enable it to switch to electronic payment system and its application.

2. Encourage government institutions, especially the Baghdad Municipality / Baghdad Water Department to adopt and apply modern means to keep pace with technological development and use modern methods to improve the reality of services provided to citizens and improve their quality and thus maximize their revenues.

-3Developing the technological culture of society by using modern electronic means in completing transactions to accept change .

\section{Research Methodology}

The researcher relied on the case study methodology (Case study It is a scientific approach that corresponds to the research problem and helps to collect the necessary data and information that are directly related to the research problem in addition to the advantages of this approach that it is multi-methods to obtain data such as the adoption of personal interviews or field cohabitation or observation that the researcher is an employee of the organization Researched.

\section{LIMITATIONS OF RESEARCH}

1- Spatial boundaries: The research was conducted within the limits of the Municipality of Baghdad has been selected circle of Baghdad 's water community to search.

2. Time Limits: This research was conducted for the period between $2 / 1 / 2018$ to $15 / 9 / 2018$ and includes the duration of visits and interviews in addition to the workshop.

3. Human Boundaries: A random stratified sample was selected with different functional grades in senior departments, directors, assistants, heads of departments and divisions in the department under consideration, as well as the Central Committee team formed by the Municipality of Baghdad to study the building of the integration of its systems to start working electronic collection project (electronic payment).

Q LADIS A- Description community sample Search:

1- research community:

Representing the community by choosing the Baghdad Water Department, one of the departments of the Baghdad Municipality to apply the field side of the research to express pride and appreciation to the organization to which the researcher belongs, which is responsible for the delivery of safe drinking water to all neighborhoods and areas of the capital Baghdad

\section{The research sample:}

A sample was chosen intentionally and included a group of employees who hold positions of responsibility and decision-makers and heads of departments and divisions and experienced staff and practice in the department under investigation, and therefore the total sample of the research (15) distributed according to their functional and administrative positions in the department under research and table (1) shows the results Descriptive analysis of identifying information to detail the characteristics of the research sample.

Table : 1 Descriptive analysis of identifying information

\begin{tabular}{|c|c|c|c|}
\hline percentage & the number & Category & Attribute \\
\hline $86.67 \%$ & 13 & Male & \multirow[t]{2}{*}{ Gender } \\
\hline $13.33 \%$ & 2 & female & \\
\hline $100 \%$ & 15th & \multicolumn{2}{|l|}{ Total } \\
\hline $0 \%$ & $\overline{\mathbf{0}}$ & Less than 25 years & \multirow[t]{2}{*}{ Age } \\
\hline $0 \%$ & $\overline{\mathbf{0}}$ & From 25 years to less than 30 & \\
\hline
\end{tabular}




\begin{tabular}{|c|c|c|c|}
\hline $0 \%$ & $\mathbf{0}$ & From 30 years to less than 35 & \\
\hline $13.33 \%$ & 2 & From 35 years to less than 40 & \\
\hline $86.67 \%$ & 13 & 40years and over & \\
\hline $100 \%$ & 15th & Total & \\
\hline $26.67 \%$ & 4 & Director general & \multirow[t]{5}{*}{ Career Level } \\
\hline $13.33 \%$ & 2 & Assistant General Manager & \\
\hline $33.33 \%$ & 5 & Director of the Department & \\
\hline $26.67 \%$ & 4 & Division official & \\
\hline $\mathbf{0 \%}$ & $\mathbf{0}$ & Unit Administrator & \\
\hline $100 \%$ & 15th & \multicolumn{2}{|l|}{ Total } \\
\hline $6.67 \%$ & 1 & Ph.D. & \multirow[t]{5}{*}{ Qualification } \\
\hline $6.67 \%$ & 1 & M.A. & \\
\hline $13.33 \%$ & 2 & Higher Diploma & \\
\hline $66.67 \%$ & 10 & $\mathbf{B A}$ & \\
\hline $6.67 \%$ & 1 & diploma & \\
\hline $100 \%$ & 15th & \multicolumn{2}{|l|}{ Total } \\
\hline $6.67 \%$ & 1 & expert & \multirow{8}{*}{$\begin{array}{l}\text { Title } \\
\text { Career } \\
\text { Present }\end{array}$} \\
\hline $6.67 \%$ & 1 & Director general & \\
\hline $46.67 \%$ & 7 & Chief Senior Engineer & \\
\hline $6.67 \%$ & 1 & Senior Account Manager & \\
\hline $6.67 \%$ & 1 & Chief statisticians & \\
\hline $6.67 \%$ & 1 & Senior Accountant & \\
\hline $13.33 \%$ & 2 & Associate Director & \\
\hline $6.67 \%$ & 1 & Manager & \\
\hline $100 \%$ & 15th & \multicolumn{2}{|l|}{ Total } \\
\hline $\mathbf{0 \%}$ & $\mathbf{0}$ & Less than 10 years & \multirow{6}{*}{$\begin{array}{l}\text { Years of } \\
\text { service }\end{array}$} \\
\hline $6.67 \%$ & 1 & From 10 years to less than 15 years & \\
\hline $20 \%$ & 3 & From 15 years to less than 20 years & \\
\hline $13.33 \%$ & 2 & 20years to less than 25 years & \\
\hline $13.33 \%$ & 2 & $25 y e a r s$ to less than 30 years & \\
\hline $46.67 \%$ & 7 & 30years and over & \\
\hline $100 \%$ & 15th & Total & \\
\hline
\end{tabular}

\section{THE SECOND TOPIC: PREVIOUS STUDIES}

This research includes a brief overview of the most important of some of the previous studies as it is an important aspect of any new studies as it enables the researcher to know his research, which had a great impact in enriching the research, and within this research will be a summary of a number of previous studies Iraqi,Arab and foreign According to their chronology, these studies are also discussed in this paper.
1- a study (Kumaga, 2010 (Entitled the challenges of implementing the systems of payment estate system payment mail in Ghana has aimed this study to focus on the challenges that affect the adoption and application of the system of electronic payment in Ghana which represented PAL) issues of security structures and infrastructure issues, legal and regulatory issues, social and cultural .(The use of the questionnaire and interviews deep as a tool to collect data study highlights were the results of the study, although the payment electronic system 
has the benefits of its application, but he faces some challenges represented by the social and cultural aspect which is the main challenge because of the high rate of illiteracy for most Ghanaians being's not on awa re of the benefits of payments of electronic and therefore are slow to adopt, also lack some of the banks to understand and benefit from

the advantages of electronic payment, which calls for the need for programs of training for the management of senior banks.

2. a study (Ngereza \& Iravo, 2013 (Entitled challenges that affect the implement ation of the systems of payment e : study the case of company lines Air Kenya , the aim of this study to focus the factors that affect the adoption and application of the system of electronic

payment for sector aviation in line air Kenyan and $r$ epresented by the Basel ) issues regulatory and legal, and the challenges of social and cultural structures and infrastructure, and the barriers to financial, and obstacles institutional barriers political, and measur es of security bad.( The use of the questionnaire and interviews as a tool for data collection, through the results show that the payment system in the airline of Kenya was not effective and should be added to the lack of a policy to train staff on the system, which calls for emphasis the need to create programs of training for staff as well as to maintain a culture of regulatory high added to other influencing factors.

3. a study (Elbasir, 2015 (Entitled the study of factors affecting the adoption of the electronic payment system in Libya it was aimed at this study to focus on the factors that affect the adoption and use of the system Electronic payment, and how it positively or negatively affects the desire of customers Organizations in the adoption of the payment system electronic in Libya, has been used interviews as a tool to collect data from the sample, the results showed that the factors of social, organizational, economic, political and technical respectively affect the
Libyan consumers and that it is likely that the organizations adopt payment electronic system in payment systems by.

4. Study (2018Nguyen \& Huynh, (Entitled Risk roles and perceived confidence in the adoption of e - payment study aimed this to investigate the role of risk Mansoura and confidence on the adoption of electronic payment, to measure the impact of factors affecting the adoption of e - payment for users of e-commerce, the use of the questionnaire as a tool to collect data from the sample, and has been Highlights : Confidence has a direct and indirect impact on the adoption of electronic payment. Furthermore, demographic information can also be considered as an intermediate variable on the acceptance and use of electronic payment systems.

\section{Discussion of previous studies:}

By looking at the previous studies that are close to the current research topic and after reviewing the studies in all their details above, some studies dealt with the challenges and obstacles facing the adoption of electronic payment systems, which were represented by organizational and legal issues, social and cultural challenges, infrastructure, financial, institutional, and obstacles. Political, security issues. In addition to perceived risks and consumer confidence, and other studies dealt with the most important factors affecting the adoption of the electronic payment system and its application, while other studies dealt with the evaluation of electronic payment systems and what benefits resulted from the adoption of this system. Which benefited the researcher through briefed on these studies in the development of research questions, as well as enriching the theoretical framework of the current study, and make use of them in the selection of research tools. The current study is consistent with previous studies that all e-business) emanagement, e-government, e-payment) is a way to reduce business routines and reduce time and effort and reduce costs, as well as help to maximize revenue. And what distinguishes this study from previous studies addressed to the subject of the requirements of the regulatory and financial for the shift to electronic payment through which seeks 
to find out what are the All requirements of the crisis to shift the Li electronic payment system and adopted, and this in turn is marked for this study, the fact that most of the previous studies Addressed the factors that affect the adoption of electronic payment systems and the challenges that hinder the adoption of this system. And the researcher believes that what distinguishes this study is almost unique to the level of other special studies Iraqi studies on the subject of the transformation requirements of the traditional payment to electronic payment.

\section{First topic}

\section{$\underline{\text { Traditional payment }}$}

In this paper, the traditional payment system, its history, development and the means of payment are reviewed as follows:

\section{What is traditional payment:}

The system of payment in any country of the world is determined by many factors represented by social, economic and historical factors and the developments of technological culture of society, as the form and method of use of payment methods in any country is determined in the light of these factors. The world today is characterized by the form of cash exchange, as it requires that we do daily millions of complex calculations in which goods must not be similar, which requires a consensus among all societies by relying on something that is generally accepted as a means of payment that can be accepted by society They are money) Hamzi, 2002: 14). The system of payment has been defined by writers and researchers in several definitions. (Hussein, 2009) believes that the concept of payment system: it reflects a set of institutions, rules, regulations, channels and tools through which payment between organizations) Qalqul,.(32:2013

Over time, a number of problems have arisen with the use of traditional payment tools, which many suffer from due to excessive procrastination and some of them have been addressed (Wahiba, 2011: 39):

1- Inadequate traditional payment instruments: The increased need for personal presence of both the merchant and the customer impedes the freedom of transactions.
2. Insecurity: Traders can commit fraud, falsification of signatures, credit card numbers can be stolen.

3. Payment delays on time: Traditional payments are not made on time and the reason for this depends on the actual verification of the quality of payment, and the adoption of manual methods lead to straining customers because of waiting in long lines.

4. Problems of an administrative nature (query requests, check books, mail receipt and proof documents) Each of these steps forces the customer to move from one place to another.

5. Rarely send periodic statements and accounts summaries to the customer's residence and may be non-existent.

.6Increased costs: due to traditional procedures and contexts, the customer incurs a fixed amount of money to complete transactions.

\section{The second topic \\ Electronic payment and its requirements}

\section{First: The concept of electronic payment:}

E-payment is an important form of technological innovation and a new way of doing business (Lubanga et al, 2017: 29), As the emergence of the electronic payment era is the emergence of real technology) Belaada 0.2018: 327) has the latest information technology and communications revolution in the growth of traditional payment systems. People can pay for goods and services online instead of traditional methods of cash. Electronic payment systems have a variety of features, some of which include time, convenience, transparency, safety and cost savings in transactions (Gholami et al 2010: 51).In addition, online payments are made through digital information, and the primary purpose of payment transactions is achieved by digitally transferring information (Min, 2015: 38).He sees) and behind Aljaddaah 2008: 231 (The electronic payment system: It is a payment system that is made electronically instead of paper (cash, sukuk) as any person can be charged on his electronic bills or can transfer money electronically through his own bank account. Electronic payment has also been defined as a set of steps that start with the transfer order issued by the beneficiary in order to pay the beneficiary of the order. This is done 
electronically, including any order issued by the ordering bank, or the intermediary bank aimed at executing the order of payment order, and the transfer is accepted by a bank. The beneficiary shall pay the requested amount in favor of the beneficiary indicated in the order) Dababash and Hisham, 2017: 104) .It is worth mentioning that the Iraqi law defined electronic payment: " a set of means, procedures and rules for the process of transferring funds between participants within the system to be the transfer of funds through the use of the infrastructure of payment systems") Law No. (3), 2014: 3). Figure (1 (illustrates the payment process by adopting electronic payment.

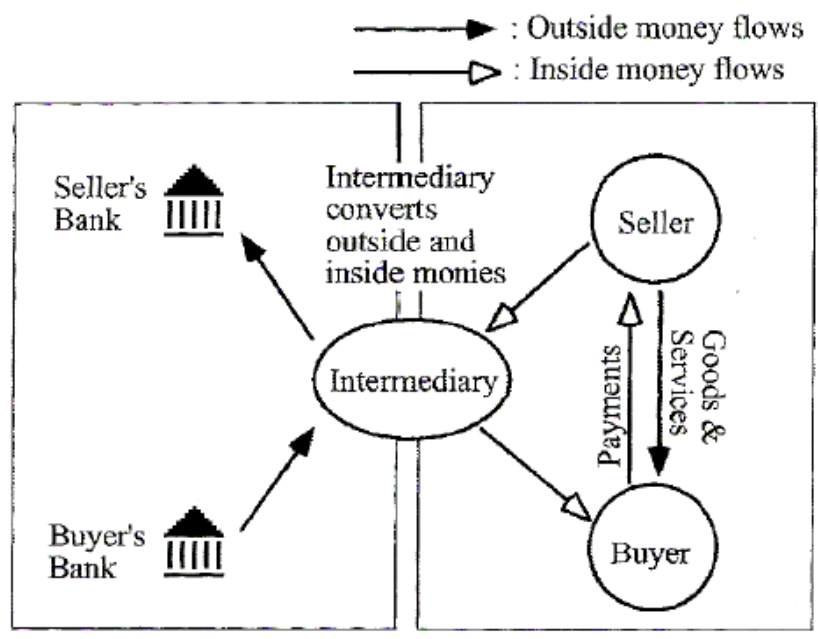

Figure (3)illustrates the payment process by adopting electronic payment

Source: Sumanjeet, Singh. (2009: 23) "Emergence of payment systems in the age of electronic commerce: The state of art." Global Journal of International Business Research

And the above is clear that there are parties to the electronic payment and these parties as stated both (Pant, 2011: 14) (Noonan, 2015: 8) And) Ismail 2018: 28):

1- Seller or Merchant: This is the party that collects and receives the electronic payment from the customer.

2. Customer, or Beneficiary: means the party making the payment electronically for the purpose of purchasing goods and services.

3. Regulator: This is the process of regulating epayment, often by government departments.

4. Electronic Clearing House: It is the electronic network through which funds are transferred between banks.

5. Issuer means the issuer of the electronic payment instrument.

Second - A- reasons to switch to electronic payment:
There are reasons for the emergence of electronic payment as a result of developments in ICT (ICT( In the field of transactions between companies and their customers, electronic payment systems have become more attractive to large financial institutions as they are adapted to meet the new requirements of ebusiness as they are very good opportunities to convince customers to complete their business through Internet (Heng, 2004: 1) .More specifically , it has emerged as a way to solve some cash-related problems such as the need to reduce the cost of money, making small purchases and spot payments more flexible, relieving beneficiaries of temporal and spatial constraints, and to increasing security and protection from fraud and other types of potential crimes. (Liébana-Cabanillas et

al, 2014: 224). Traditional payment systems have many constraints that prevent beneficiaries from adopting them. Previous research indicates that some of these 
factors are related to lack of confidence, security, ease of use, high transaction costs, lack of perceived advantage and perceived risks. All of these factors are important for the transition to online payments (Özkan et al, 2010: 305).E-payment is able to increase efficiency, reduce fraud and create innovation in the channel-assisted payment industry; ATMs, Internet Banking, Mobile Banking and POS terminals. This innovative system allows the transfer of funds between several financial institutions in the period Short time. Efficiency in the electronic payment system can be seen by comparing the traditional electronic payment system in terms of payment method, payment time and features. The form of payment for online payment is made directly to the account and can be made at any time. In the traditional payment system, payment must be made manually and customers must present it to the bank. Electronic payments can save time in payment transactions because they can be made on the same day, 365 days a year, but in the traditional system, the minimum takes two business days and can only be made on business days. In addition, the special advantage of electronic payment is that it exists everywhere (Mohamad \& Kassim, 2017: 52).

From the above, it is clear that the reasons for the transition and adoption of electronic payment technology are due to the emergence of some problems in the traditional payment methods in terms of time, costs and security, in addition to technological development and the widespread use of the Internet by various segments of society helped to adopt electronic payment methods being available everywhere and time plus it limits the routine to complete transactions.

\section{Third A- benefits of electronic payment:}

There are several benefits of electronic payment. The adoption and dissemination of the culture of electronic payment can enhance the effectiveness and efficiency of the economic system as governments try to encourage their citizens to adopt electronic payment systems because it can save costs from the production of paper money, also can force companies to pay taxes using electronic payment As monitoring tools, in addition, people can benefit from the use of electronic payment when purchasing products or services online or other electronic systems without actually having to send money. Moreover, ePay provides businesses with the opportunity to connect with customers around the world (Chaiyasoonthorn \& Suksa-ngiam, 2019:
102). What unites everyone, whether they are online merchants or beneficiaries, is that they want to get money for their goods and services (Key \& Wiedemann, 2005: 334).It is worth mentioning that electronic payment provides the possibility of completing transactions in a safe, transparent and reliable and faster as it reduces the proportion of errors, costs and risks, as it provides a high possibility to increase the number of customers maximize the returns of banks, especially as it is an attractive investment for the future) Central Bank of Iraq, 2006).

Fourth A- types of media paying off e: -

Means of payment: A tool or set of procedures that enable the transfer of funds from the payer to the beneficiary. There are a variety of different payment methods, each with their own characteristics depending on the type of relationship and transaction between the payer and the beneficiary (Kokkola, 2010: 28) .That is, it enables the holder to access funds held on his account and usually requires a PIN or other similar proof of identity. (Schudelaro, 2001: 105). There are a large number of online payment services that have been developed within the worldwide payment system. It has been classified by both (Sumanjeet, 2009: 18), (Kavu et al, 2013: 2) And (Islam Khan B. et al, 2017: 3) Into four main categories is a system of payment by credit card online, and the system of e - cash online, electronic checks, and electronic payment systems based on smart cards of and as follows:

\section{1- Electronic payment cards:}

It is a plastic card with cardholder information that can be used for payment purposes. Generally, payment cards offer cash from ATMs, direct payment to vendors with POS, and online payment (Maurizio, 2011: 17). There are types of electronic payment cards as follows:

\section{1- Plastic Cards: Bank Cards}

Plastic cards are used to pay for goods and services at the time of purchase. These cards free the holder from the burden and risk of carrying large amounts of money or instruments that may be stolen or damaged and lost, especially as they need a personal identification number to deal with them (Ahuja, 2019: 27). These cards allow the holder to obtain cash through ATMs (ATM()Ben Younes, 2018: .(15It has several types and figure (1 $(\mathbf{9}$ shows the types of these cards. 
-1a- credit cards Credit Cards: Defined as a payment card issued by a bank or finance company, which allows the holder to either pay for goods and services directly at points of sale or online or to obtain cash advances up to an agreed credit limit to be paid in the future (Kahf \& Mohomed, 2016: 60). And knew) Husseini .2019: 29) as a plastic card is made of the material is difficult to tamper with a cell inside Ketr and the intention of working on information storage and personal data bearer, such as name, date of birth, address and the source of the card. Issued by a specific entity (bank or institution) to users for online or offline money transfers .Credit cards are the most widely used form of electronic payment) Kim et al, 2010: 86). A credit card is established between three issuers: the issuer of the payment card to the beneficiary (the cardholder), which is a financial institution or its agent. The beneficiary (cardholder) is the person using the credit card for the payment transaction. The Cardholder will contract with the card issuer to provide the goods and services he / she has when requested by the Cardholder from the Bank (Radu, 2003: 6) :It is worth mentioning that there are two types of credit card (credit card renewable credit card and non - renewable)) Ishmael,.(38 :2018

-2a- cards not credit on-Credit Cards: Also called an instant debit card, these cards are used as a tool for fulfillment only) Ismail, 2018: 37) .This type of card is the most widespread in the world because it reduces the risk of bad debts of the banks that issue these cards because they are characterized by that they do not give any credit to the holder) Zawash, 2011: 28). They are in several types) debit cards ,prepaid cards ,ATM cards(

2. smart card Smart Cards :Is the card plastic credit card - sized containing an electronic chip small compact, with the ability to store and retrieve data and information bearer, including account numbers and lines of credit and other data that can allow use - card credit card discount cards paid in advance. In addition, a smart card may contain personal information, such as health data (Turner \& Wunnicke, 2003: 195). .It does not require bank approvals for each transaction (OâMeara et al, 2000: 301). There are two types of smart cards) connected and offline)) Ismail, 2018 :.(36

2. Electronic money: is a form of electronic payment like a just like the traditional cash, allow the money to complete transactions between clients without having to banks or any other third party. E-money is transferred directly to vendors and vending machines. E-cash is a safe and convenient alternative to banknotes or coins. Most electronic money is transferred directly from the buyer to the seller's website (Ahuja, 2019: 28) .Can be either certified electronic money on devices (for example, it is stored on a device usually card) or a list of programs (which are stored on a computer). Emoney is a means of settlement and not a means of payment. E-money is created or paid using one of the primary payment instruments - cash, payment cards, direct debit or credit transfers. (Kokkola, 2010: 30)

3. Electronic instruments: A form of electronic payment, designed to work the same way with a traditional (paper) instrument. But the main difference between an electronic instrument and a paper instrument is that the actual money is deducted or Deposit electronically using electronic instrument is considered Electronic instrument is the least popular compared to electronic payment methods (Oney et al, 2017: 397).

$.4 \mathrm{e}$ - wallet (digital) :is the portfolio of electronic as money for the bearer, but with a different form of being a financial value stored electronically on a device such as the card has a magnetic tape works on the information storage, allows electronic wallet money transfer from the card to another or to someone else Or for a shop without a middleman as the e-wallet is an alternative to cash in the payment of daily transactions and used in small payments) Ismail, 2018: 39) .

V. - distribution channels and means paying off e: -

1- ATM: Automated Teller Machine (ATM)It is a programmed machine in which to store money in a certain way that works to provide services to customers to facilitate their need and preserve their time, but it is of a specific nature by the amount of cash and the number of withdrawals as it does not allow the possibility of repeated withdrawals for 
the same number on the same day) Husseini, 2019: 26) .ATM networks connect ATMs to a particular bank or group of banks, allowing cardholders to use the ATMs of the network regardless of their location. (Kokkola, 2010: 34).

2. Terminal units in sales centers Point of Sale Service (POS): Is a computer used in the sales and shopping centers connected to the computer in the bank allows direct transfer of funds from the account of the customer (the buyer) to the account of the seller through his cards) Ismail, 2018: .(39The method first developed in the early to mid-1980s and became a leading payment system for goods and services (Chakraborty \& Ennew, 2007: 24).

3. Digital TV Digital Television: It is one of the latest distribution channels for electronic payment methods as it enables banks to deal with their customers in their locations, especially in homes. Through satellites as a link between the customer and his electronic account in banks, the customer can access his account through a secret code to complete the financial operations he wants) Ismail, 2018: .(40

- 4home banking Home Banking: A service that allows customers to access their account information via a private network, usually with the help of special software installed on their computers. To provide customers with 24-hour services, customers can use their personal computers at home or in their office to access their accounts in order to pay for transactions. The PC has the advantage of reducing cost, increasing speed and improving the flexibility of financial transactions. (Guru et al, 2000: 6).

5. mobile phones Mobile payments :Electronic value storage is used for portable devices (mobile) to conduct financial transactions (such as Internet service payments, pay utility bills, mobile banking services), that money services mobile enables one directly on the mobile phone, to use this value to buy a wide range of Products and services with short time, effort and lower cost (Eelu \& Nakakawa, 2018: 222),

- 6Internet banking Internet Banking :The proliferation of Internet networks has enabled most organizations to deal with customers through the Internet without the trouble of going to the institutions to complete transactions, as the dialogue between the customer and service providers through the computer screen) Ismail, 2018: 40).

\section{CHAPTER III: PRACTICAL ASPECT}

First: the validity tests of the stability of the measuring instrument examination form

1- Honesty test: The test virtual honesty results for the paragraphs of the requirements of the regulatory amounted to $(0.821)$ high percentage showing the arbitrators agreement on eight paragraphs of the ten paragraphs of which the allocated to the requirements of human resources, but for the entire paragraphs of the financial requirements amounted to the value of stability coefficient (0.772 This value indicates that the financial requirements are successfully exceeded $(0.700)$.

.2Test stability: The stability of the most important conditions to be provided by a search form, especially that confirms the reliability of the data $\mathrm{C}$ share for the researcher of the sample aas the value of the stability coefficient) Cronbach's AlphaThe total paragraphs of human resources requirements amounted to $(0.821)$ ، indicating a high stability in the seven paragraphs of human resources requirements due to being more than $(0.700)$.

Second descriptive analysis of the requirements of the regulatory and financial for the electronic payment

The researcher based on three statistical measures represented by the weighted arithmetic media and standard deviations and relative importance, as the researcher applied these measures to each paragraph of the requirements of electronic payment (human requirements, ( but to show the direction of the answer to the paragraphs the researcher adopted the hypothesis medium (1) Which is the boundary between availability and non-availability within a metric) Likert)The triple used in the study, but to determine the level of response of the respondent on the paragraphs of the questionnaire, the researcher based on the matrix of the response force of the respondent, which represents 
Table (2) Response Force Matrix on Questionnaire Paragraphs

\begin{tabular}{|l|l|l|}
\hline Response level by the responder & $\begin{array}{l}\text { The power of response on the } \\
\text { resolution paragraphs }\end{array}$ & $\begin{array}{l}\text { The weighted average value is } \\
\text { limited to the period }\end{array}$ \\
\hline Low & not available & From 0 to less than 0.67 \\
\hline Average & Somewhat available & From 0.67 to less than 1.34 \\
\hline High & available & From 1.34 to 2 \\
\hline
\end{tabular}

Note from the table (11)that if the center value of the arithmetic likely range (0 to less than 0.67$)$, the strength of the response means is not available at the same time the level of response by the respondent to be low, but if the arithmetic mean weighted value between ( 0.67 ranged to less than 1.34), the strength of the response means available to some extent accompanied by the level of response by the respondent to be average, whereas if the arithmetic mean weighted value of the range (from 1.34 to 2) the strength of the answer means available and at the same time , the level of response by Effector be elevated. In particular, the length of the class in the response power matrix was calculated by dividing the equation (the highest value taken by the scale used in the message minus one integer) divided by (the highest value taken by the scale) which equals (0.67).

\section{1- Descriptive analysis of regulatory requirements :}

Table (3)that the weighted mean of regulatory requirements recorded (1.767), which is greater than the value of the hypothetical mean, which represents the boundary between the availability and non-availability of (1)which confirms that the direction of answers regarding regulatory requirements tended towards availability, where the value The weighted arithmetic mean of the regulatory requirements within the category (from 1.34 to 2) in the effector's response strength matrix, indicating that the level of response of the respondent to most paragraphs of the regulatory requirements was high, with a standard deviation of (0.246) which indicates a slight dispersion in The research sample answers regarding the requirements of the regulation The relative importance of these requirements was recorded $(88.3 \%)$, which shows the agreement of most of the sample of the research on the paragraphs of regulatory requirements, and we conclude that most of the regulatory requirements are available in the Baghdad Water Department/Baghdad Municipality.

Levels were distributed sample responses to the study on the requirements of paragraphs organizational between the highest level of response by the respondent achieved paragraphs) q 1 , q2, q4, q5, q8 (Reached a weighted mean (2)for each of them and the standard deviation was zero for each of them, and the relative importance of formed (100\%As shown in Table ( 3 )

Table (3) the level of responses of the sample to the paragraphs of regulatory requirements

\begin{tabular}{|c|c|c|c|c|c|c|c|c|c|c|c|}
\hline \multirow{3}{*}{$\begin{array}{l}\text { Response } \\
\text { level } \\
\text { Effector }\end{array}$} & \multirow{3}{*}{$\begin{array}{l}\text { The } \\
\text { relative } \\
\text { importance }\end{array}$} & \multirow{3}{*}{ Std. Deviation } & \multirow{3}{*}{$\begin{array}{l}\text { Weighted } \\
\text { Mean }\end{array}$} & \multicolumn{6}{|c|}{ the scale } & \multirow{3}{*}{ Paragraphs } & \multirow{3}{*}{ code } \\
\hline & & & & \multicolumn{2}{|c|}{$\begin{array}{l}\text { not } \\
\text { available }\end{array}$} & \multicolumn{2}{|c|}{$\begin{array}{l}\text { Somewhat } \\
\text { available }\end{array}$} & \multicolumn{2}{|c|}{ available } & & \\
\hline & & & & $\%$ & $\mathbf{T}$ & $\%$ & $\mathbf{T}$ & $\%$ & $\mathbf{T}$ & & \\
\hline & & & & \multicolumn{2}{|l|}{$\mathbf{0}$} & \multicolumn{2}{|l|}{1} & \multicolumn{2}{|l|}{2} & \multicolumn{2}{|l|}{ Weights } \\
\hline & & & & \multicolumn{2}{|l|}{1} & \multicolumn{2}{|l|}{33} & \multicolumn{2}{|c|}{116} & \multicolumn{2}{|l|}{ Duplicates } \\
\hline & & & & \multicolumn{2}{|l|}{$\mathbf{0}$} & \multicolumn{2}{|l|}{33} & 232 & & \multicolumn{2}{|c|}{ Weights * Duplicates } \\
\hline high & $88.3 \%$ & 0,246 & \multicolumn{7}{|l|}{1.767} & \multicolumn{2}{|c|}{ Weighted mean } \\
\hline \multicolumn{10}{|l|}{0.88} & \multicolumn{2}{|c|}{ Matching extent } \\
\hline
\end{tabular}




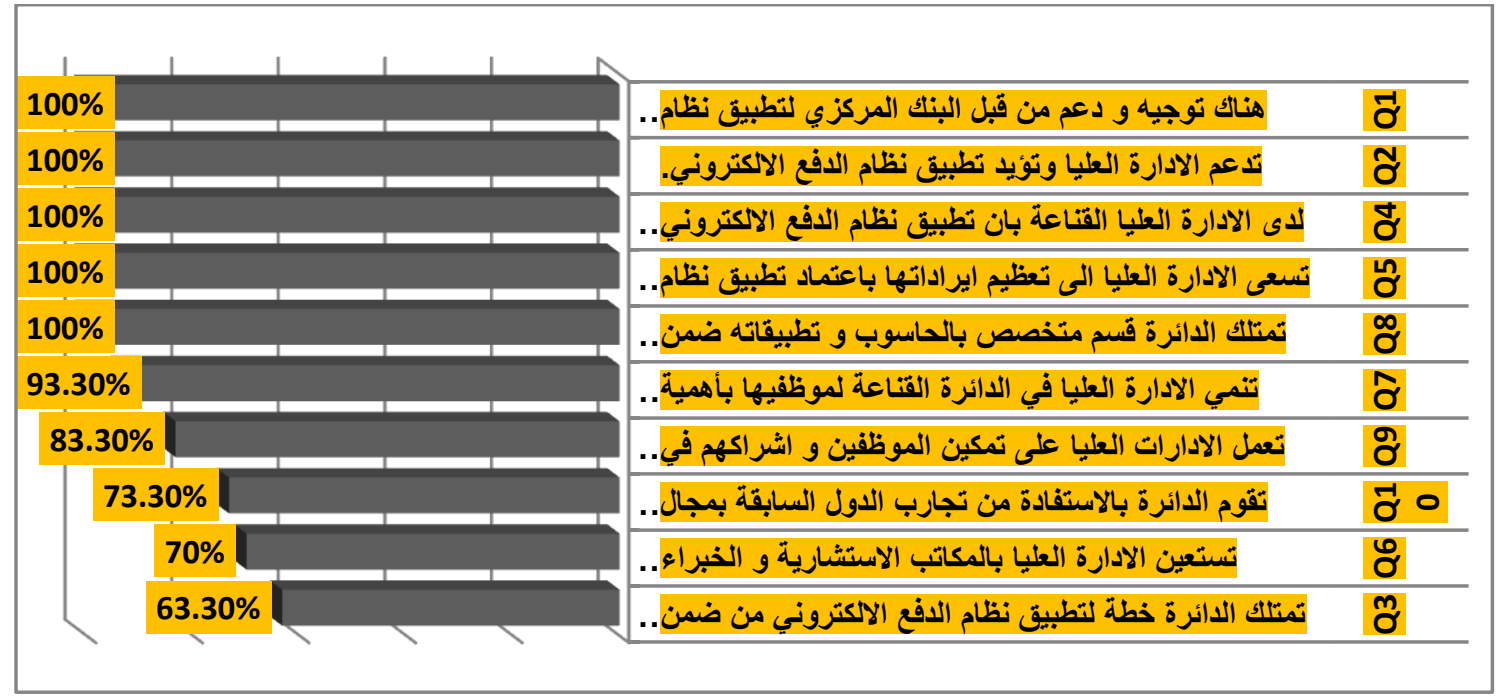

Figure (2) Distribution of paragraphs of regulatory requirements according to the proportion of availability

\section{2- Analysis of financial requirements:}

Table ( $(\mathbf{4}$ achieved that the weighted average value of financial requirements was (1.167), which is greater than the hypothetical mean, which represents the boundary between the availability and nonavailability of ( 1 ) which confirms that the direction of answers regarding financial requirements tended towards availability to some extent, The weighted mean of the financial requirements within the category ranged from $(0.67$ to less than 1.34$)$ in the respondent strength matrix, indicating that the level of response of the respondent to most paragraphs of the financial requirements was an average level, with a standard deviation of (0.391), which Indicates that there is a slight dispersion in the answers of the research sample in relation to the requirements paragraphs The relative importance of these requirements was also recorded (58.3\%) indicating the agreement of more than half of the respondents on the paragraphs of financial requirements, from which we conclude that financial requirements are available to some extent in the Baghdad Water Department/Baghdad Municipality.
The level of responses of the research sample to the paragraphs of financial requirements was divided between the highest level of the response of the respondent achieved in paragraph (14 )with a weighted mean of (2)each and a standard deviation of zero each, and a relative importance formed (100\%) As shown in Table (4) and Figure (3) confirming the agreement of all members of the study sample on

The Baghdad
Department / Baghdad Municipality
the financial allocation for the rovides
design
and development of electronic programs, while the
paragraph (15) achieved the lowest level of
response among all paragraphs of financial
requirements, where the value of the weighted
mean of this paragraph (0.067) was the standard
deviation ( And the relative importance of
(3.33\%)to confirm this agreement most of the
sample of the study on the lack of financial
allocation to motivate outstanding employees in the
field of electronic business in the Baghdad Water
Department / Baghdad Municipality.


Table (4): Level of responses of respondents to paragraphs of financial requirements

\begin{tabular}{|c|c|c|c|c|c|c|c|c|c|c|c|}
\hline \multirow{3}{*}{$\begin{array}{l}\text { Response } \\
\text { level } \\
\text { Effector }\end{array}$} & \multirow{3}{*}{$\begin{array}{l}\text { The } \\
\text { relative } \\
\text { importance }\end{array}$} & \multirow{3}{*}{ Std. Deviation } & \multirow{3}{*}{$\begin{array}{l}\text { Weighted } \\
\text { Mean }\end{array}$} & \multicolumn{6}{|c|}{ the scale } & \multirow{3}{*}{ Paragraphs } & \multirow{3}{*}{ code } \\
\hline & & & & \multicolumn{2}{|c|}{$\begin{array}{l}\text { not } \\
\text { available }\end{array}$} & \multicolumn{2}{|c|}{$\begin{array}{l}\text { Somewhat } \\
\text { available }\end{array}$} & \multicolumn{2}{|c|}{ available } & & \\
\hline & & & & $\%$ & $\mathrm{~T}$ & $\%$ & $\mathrm{~T}$ & $\%$ & $\mathrm{~T}$ & & \\
\hline & & & & \multicolumn{2}{|l|}{$\mathbf{0}$} & \multicolumn{2}{|l|}{1} & \multicolumn{2}{|l|}{2} & \multicolumn{2}{|l|}{ Weights } \\
\hline & & & & \multicolumn{2}{|l|}{27} & \multicolumn{2}{|c|}{21} & \multicolumn{2}{|l|}{42} & \multicolumn{2}{|l|}{ Duplicates } \\
\hline & & & & \multicolumn{2}{|l|}{$\mathbf{0}$} & \multicolumn{2}{|c|}{21} & \multicolumn{2}{|l|}{84} & \multicolumn{2}{|c|}{ Weights * Duplicates } \\
\hline Average & $58.3 \%$ & 0,391 & \multicolumn{7}{|l|}{1,167} & \multicolumn{2}{|c|}{ Weighted mean } \\
\hline \multicolumn{10}{|l|}{0.58} & \multicolumn{2}{|c|}{ Matching extent } \\
\hline \multicolumn{10}{|l|}{0.42} & \multicolumn{2}{|c|}{ The size of the gap } \\
\hline
\end{tabular}

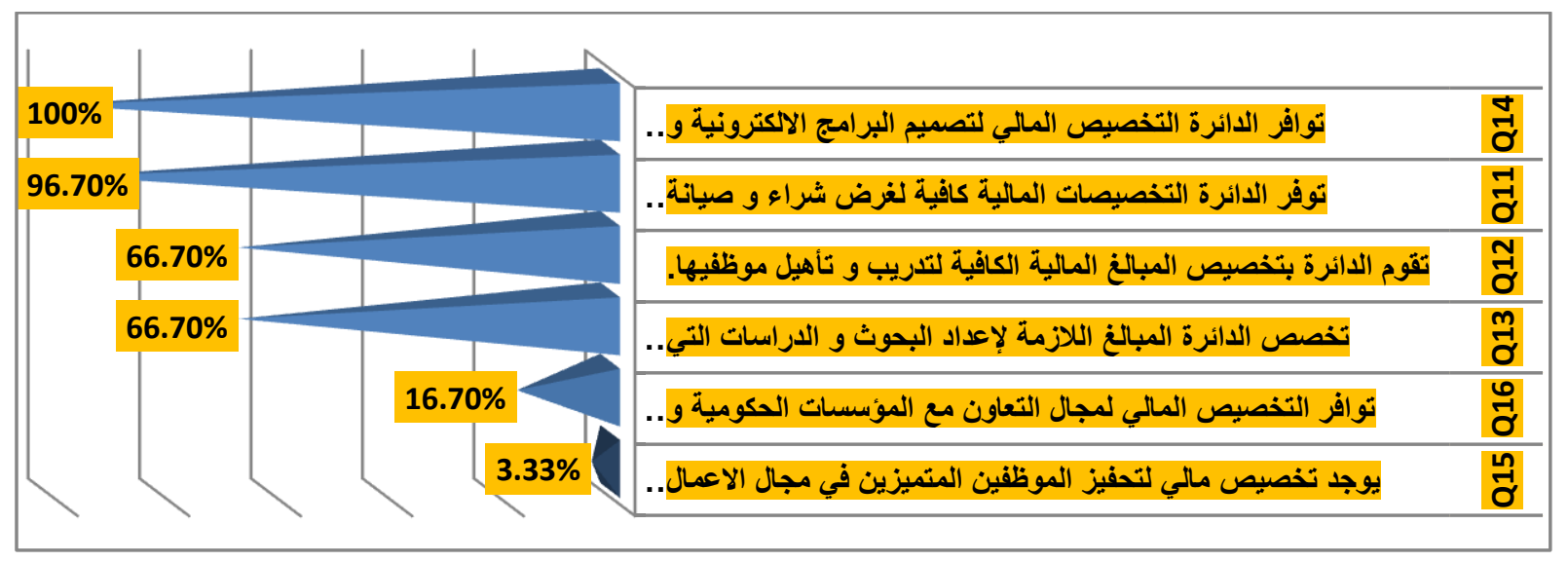

Figure (3): Distribution of paragraphs of financial requirements according to the percentage of availability

\section{THE FOURTH CHAPTER: CONCLUSIONS}

By analyzing the results of the questionnaire, the researcher found the following conclusions:

1- T provided the support by the administration upper and supports the application of the system of payment mail.

2. There is a plan to implement the electronic payment system as part of its strategic plan.

3. Administration Supreme has the conviction that the application of the system of payment mail works on the limit of the business routine.

4. It works department senior in the department on the development of the conviction of its employees the importance of adopting the methods of electronic in the process of collection.

5. The department has a specialized computer depa rtment and its applications within the organizational structure.

\section{SOURCES:}

1- Ismail, Alaa Ibrahim.(2018).Electronic payment system and its impact on the development of the insurance service - a research survey in the Iraqi General Insurance Company.

2. Belabidi, Aida Abir .(2018)The reality of modernizing payment systems in Algeria and its 
impact on the Algerian banking system. Journal of Banking Financial Economics and Business Administration.

3. Ben Younes, Ajjal Al Mansour. .(2018 )The reality of the use of electronic payment methods in the Algerian banks exploratory study in the local development bank and agency Mostaganem. Master Thesis in the Department of Science and Management Faculty of Economic and Commercial Sciences and Management Sciences.

4. Jedaia, Mohammed Noor, and Khalaf, Sana Jawdat.( 2008 ) . electronic tradeElectronic Commerce (EC). Amman, Jordan: Dar AlHamed for Publishing and Distribution.

-5 Al-Jumaily, Ahmed Mohammed Jassim. .(2018)The possibility of applying electronic management in the management of the insurance industry exploratory study in the National Insurance Company. Journal of the University City Science University Volume, 10 (2).

6. Husseini, Zahra Hadi. (2019). Activating the banking sector in light of the use of electronic payment systems in Iraq. Master Thesis in Economic Sciences / College of Business and Economics / University of Baghdad.

7- Hamizi, Sayed Ahmed.(2002 ) . Modernization of the means of payment as an element for the rehabilitation of the Algerian banking system

8- Dababash, Abdul Rauf, and Hisham, Zabih.( 2017 )The means of payment between the technical and legal protection of the electronic consumer. Journal of Jurisprudence (No. 14).

9. Zouach, Zuhair.(2011).The role of electronic payment system in improving banking transactions. Master Thesis in Economic Sciences - International Finance and Financial and Monetary Institutions - Faculty of Economics and Management Sciences - Al Arabi Bin Mahidi University - Oum El Bouaghi.

10. Abdul Rahim, and prestige. (2013). Modernization of payment methods and their contribution to the creation of electronic commerce in the Arab world, the case of Algeria.
11. Law No. (3).(2014) . Electronic Payment Services System No. (3). Iraqi Facts | Issue No: 4326 |, 3-15.

12. Electronic payments section of the Central Bank of Iraq.(2006).

13. Qalqul, unique. (2013) The importance of electronic payment systems in banks.

-14 Mahfouz, quality. (2009) . Advanced Statistical Analysis) Volume II Edition). Amman: Wael Publishing House.

15th- Saved, quality.(2010) . Advanced Statistical Analysis) Vol. 1 st ed.). Amman: Wael Publishing House.

16. Chosen, and are (2019). Electronic Management in the Arab Countries (Requirements and Challenges).

17. Al-Naimi, Mohammed Abdel-Aal, and food Hassan Yassin. (2008) .Applied Statistics) Volume 1). Amman: Wael Publishing House.

18- Ahuja, K. (2019, January-June). Challenges For Indian E-Payment System. Mти Journal of Management Practices Vol. 10 (1).

19- Ahuja, K. (2019, January-June). Challenges for Indian E-Payment System. Mmи Journal of Management Practices Vol. 10 (1).

20- Chaiyasoonthorn, W., \& Suksa-Ngiam, W. (2019). The Diffusion and Adoption of Electronic Payment Systems in Bangkok. International Journal of E-Business Research (Ijebr), 15 (2), 102-115.

21- Chakrabarty, A., \& Ennew, C. (2007,). The Distribution of Bank Services: A Review of Research and Key Trends. Institut Bank-Bank Malaysia.

22. Eelu, S, \& Nakakawa, A. The (2018). Framework Towards Enhancing Adoption of Electronic Payment in A Developing Economy: A Case of Uganda. The African Journal of Information Systems, 10 (3), 5 .

23- Elbasir, M.H. (2015). An Investigation of Factors Affecting the Adoption of E-Payment System in Libya. A Doctoral Thesis.

24- Elsheikh, Y., Cullen, A., \& Hobbs, D. (2008, 8). E-Government in Jordan: Challenges and Opportunities. Transforming Government: 
People, Process and Policy, 2 (2), Pp. 83103

25- Gholami, R., Ogun, A., Koh, E., \& Lim, J. (2010). Factors Affecting E-Payment Adoption in Nigeria. Journal of Electronic Commerce in Organizations (Jeco) 8.4: 51-67.

26- Hall, B., \& Khan, B. (2003). Adoption of New Technology (No. W9730). National Bureau of Economic Research.

27- Heng, S. (2004, May 1). E-Payments: Modern Complement to Traditional Payment Systems. E-Economics Working Paper 44.

28- Islam Khan, B., Olanrewaju, R., Masihuddin, M., \& Mattoo, MI (2017, May). A Survey On E-Payment Systems: Elements, Adoption, Architecture, Challenges and Security Concepts. Indian Journal of Science and Technology, 10 (20), 1-19.

29- Kahf, M., \& Mohomed, AN (2016, January). Credit Cards: Contemporary Issues from Economic and Shariah Perspective. Journal of King Abdulaziz University: Islamic Economics, 29 (1).

30- Kavu, T., Rupere, T., Nyambo, B., \& Hapanyengwi, G. (2013). An Electronic Payment Model for Small and Medium Enterprises in Zimbabwe. International Journal of Scientific and Engineering Research, 4 (1), 1-8.

31-Key, P., \& Wiedemann, D. (2005). Payment Procedures for Electronic Government Services. Pp. 333-341.

32- Kim, C., Tao, W., Shin, N., \& Kim, K.S. (2010). An Empirical Study of Customers' Perceptions of Security and Trust. Electronic Commerce Research and Applications, 9 (1), 84-95. A: No.

33-Kokkola, T. (2010). The Payment System: Payments, Securities and Derivatives, And The Role of the Euro system. European Central Bank.

34- Kumaga, D. (2010). The Challenges of Implementing Electronic Payment Systems The Case of Ghana's E-Zwich Payment System. Master's Thesis in Business Administration, Mba Program.
35- Liébana-Cabanillas, F., Muñoz-Leiva, F., \& Sánchez-Fernández, J. (2014). Comparative Study Among New Payment Systems and New Future Trends in Mobile Payments. Electronic Payment Systems for Competitive Advantage in E-Commerce. Igi Global A: No, Pp. 223259.

36- Lubanga, JM, Gakobo, T., Ochieng, I., \& Kimando, N. (2017). Factors Influencing Adoption of E-Payment System in Kenyan Public Transport: A Case of Matatu Plying Nairobi-Kitengela Route. International Academic Journal of Human Resource and Business Administration 2.4: 27-48.

37-Maurizio, M. (2011). E-Commerce Payment System.

38- Min, Y. (2015, 7 29). Risk and Prevention of Network Payment Industry.

39- Mohamad, S., \& Kassim, S. (2017). An Overview of E-Payment Adoption Among Muslim Micro-Entrepreneurs in Malaysia. International Journal of Accounting, 2 (5), 49-59.

40- Ngereza \& Iravo (2013) Challenges Influencing Implementation of Electronic Payment Systems: A Case Study of Kenya Airways Company.

41- Nguyen, TD, \& Huynh, PA (2018, January). The Roles of Perceived Risk and Trust On E - Payment Adoption. In International Econometric Conference of Vietnam (Pp. 926-940). Springer, Cham. A: No

42- Oâmeara, P., Mehlinger, H., Mehlinger, C., \& Krain, M. (2000). Globalization and The Challenges of a New Century A: No. Indiana University Press.A: No (No. 909.829 Om2g Ej. 1 022468).

43- Oney, E., Oksuzoglu, G., \& Hussain, W. (2017). The Determinants of Electronic Payment Systems Usage from Consumers' Perspective. Economic Research-Ekonomska Istraživanja 30.1: 394-415. A: No

44- Özkan, S., Bindusara, G., \& Hackney, R. (2010). Facilitating The Adoption of $E$ Payment Systems: Theoretical Constructs and Empirical Analysis. Journal of Enterprise 
Information Management, 23 (3), 305325. A: No

45- Pant, S. (2011). A Secure Online Payment System.

46- Pólkowski, Z., \& Radu, A.-M. (2014, 4). "T heoretical, Technical and Practical Aspects of E-Administration.". Zeszyty Naukowe Dolnośląskiej Wyższej Szkoły Przedsiębiorczości I Techniki W Polkowicach. Studia Z Nauk Społecznych, Pp. 185-210

47-Schudelaro, A. (2001). Electronic Payments:

Electronic Payments and Consumer Protection: Should Recommendation 97/489 / Ec Be Replaced with A Directive? Computer Law \& Security Review 17.2: 105-109.

48- Sumanjeet, S. (2009). Emergence of Payment Systems in The Age of Electronic Commerce: The State of Art. Global Journal of International Business Research, 2 (2)

49- Turner, P., \& Wunnicke, D. (2003). Managing The Risks of Payment Systems. Canada: John Wiley \& Sons, Inc., Hoboken, New Jersey. 